\title{
A REFORMA NA SAÚDE MENTAL NO BRASIL E SUAS VINCULAÇÕES COM O PENSAMENTO FENOMENOLÓGICO
}

\author{
Brazilian Mental Health Reform and linkages with the phenomenological thinking \\ Reforma de Salud Mental en Brasil y vínculos con el pensamiento fenomenológico
}

Mariana Cardoso Puchivailo

GUILHerMe Bertassoni DA SiLVA

Adriano Furtado Holanda

\begin{abstract}
Resumo: A reforma na saúde mental brasileira teve como grandes diretrizes, a experiência de desinstitucionalização italiana e do pensamento de Franco Basaglia. Estes, por sua vez, possuem bases e fundamentos em discussões e posições derivadas do pensamento fenomenológico (na filosofia) e de perspectivas da Psiquiatria fenomenológica, a partir de autores como Jaspers e Minkowski. O objetivo deste artigo é demonstrar as vinculações do pensamento fenomenológico na concepção da reforma da atenção à saúde mental brasileira. Para isso foi articulado teoricamente o pensamento destes autores na compreensão da saúde mental. Palavras-chave: Reforma na Saúde Mental brasileira; Fenomenologia; Psiquiatria.
\end{abstract}

Abstract: The reform of mental health had as major guidelines, the experience of Italian deinstitutionalization and Franco Basaglia's intellectual legacy. These, in turn, have bases and foundations in discussions and derivative positions of phenomenological thought (in philosophy) and phenomenological perspectives of Psychiatry, from authors such as Jaspers and Minkowski. The purpose of this article is to demonstrate the linkages of the phenomenological approach in the designing of the Brazilian reform of mental health care. Therefore was theoretically articulated the thought of these authors in the understanding of mental health. Keywords: Brazilian Mental Health Reform; Phenomenology; Psychiatry.

Resumen: La reforma a la salud mental tuvo como grandes directrices, la experiencia de desinstitucionalización italiana y el pensamento de Franco Basaglia. Estos, a su vez, tienen bases y fundamentos en los debates y posiciones en derivados del pensamiento fenomenológico (em la filosofía) y las perspectivas fenomenológicas de Psiquiatría, de autores como Jaspers y Minkowski. El propósito de este artículo es demostrar la vinculación del enfoque fenomenológico en el diseño de la reforma de la atención de la salud mental para el brasileño. Para ello se articula en teoría el pensamiento de estos autores en la comprensión de la salud mental.

Palabras-clave: Reforma de la Salud Mental en Brasil; Fenomenología; Psiquiatría.

\section{0 processo histórico de reforma na saúde mental brasileira}

No Brasil, a reforma da atenção à saúde mental tem como marco a Lei 10.216 aprovada em abril de 2001, que dispõe sobre a proteção e os direitos das pessoas portadoras de transtornos mentais e redireciona o modelo assistencial em saúde mental (Brasil, 2001). O direcionamento dado por esta Lei é o de uma atenção em Saúde Mental preferencialmente comunitária, com equipamentos territorializados, seguindo a lógica do Sistema Único de Saúde (SUS).

A partir dessa proposta, diversos serviços e equipamentos foram implantados visando atendimento substitutivo ao Hospital Psiquiátrico: os Centros de Atenção Psicossocial (CAPS), os Serviços Residenciais Terapêuticos (SRT), os Centros de Convivência e Cultura, os Ambulatórios de Saúde Mental e leitos de atenção integral em Hospitais Gerais (Ministério da Saúde, 2005).
A reforma na atenção à Saúde Mental brasileira foi formulada e desenvolvida tomando como referência diferentes reflexões teóricas e experiências práticas e, uma de suas principais fontes foi a da "Desinstitucionalização" Italiana, que Amarante (2007) divide em três períodos. O primeiro deles surge das críticas à estrutura dos hospitais psiquiátricos, que se institui após o término das duas grandes guerras mundiais. Principalmente depois do nazismo, existia certo desconforto mundial a todos os tipos de confinamento. Além disso, no período das guerras, muitos europeus morreram e vários voltaram para suas casas com "doenças mentais". Concomitantemente, havia uma busca por força de trabalho, logo, existia a necessidade de que os soldados pudessem ser tratados (Amarante, 2007).

Um dos exemplos dos processos de desinstitucionalização deste período são as Comunidades Terapêuticas, que surgem na Inglaterra nos anos 50 e 60 como alternativa e complemento ao tratamento em hospitais psiquiátricos 
(Robortella, 2000), visando liberdade de comunicação e reaprendizagem social. Este sistema receberia críticas da Antipsiquiatria e da Psiquiatria Democrática por ainda manter os hospitais psiquiátricos, e não questionar a exclusão e a responsabilidade junto a toda comunidade (Amarante, 2007). Segundo Robortella (2000), a concepção de Comunidades Terapêuticas contribuiu para a ideia da desinstituicionalização italiana, devido a sua característica de não hierarquização entre médicos, pacientes e auxiliares que participavam no tratamento da doença mental.

O segundo período se caracteriza por uma procura por soluções diferentes e substitutivas ao hospital psiquiátrico (e, portanto, à ideia de manicômio), baseada na prevenção e promoção da saúde (Amarante, 2007). Nasce, nos Estados Unidos, a Psiquiatria Preventiva, que tinha como objetivo reduzir as doenças mentais privilegiando a prevenção; o objeto da psiquiatria passa, então, a ser a Saúde Mental. Jardim \& Dimenstein (2007) colocam que os tratamentos eram realizados através de medidas "terapêuticas de urgência”, porém estas, segundo os autores, não viabilizavam novas configurações, mas apenas um enquadramento às regras já instituídas causando, frequentemente, mais sofrimento e iminentes reedições da crise.

Na psiquiatria preventiva, a situação de risco é entendida como um prenúncio do agravamento ou desencadeamento de uma suposta doença mental. Este conceito está atrelado à ideia da medicina preventiva, já que nasce a partir do cálculo estatístico da probabilidade de surgimento de alguma doença com o intuito de preveni-la. A medicina preventiva é herdeira do movimento higienista que buscava não o combate ao problema, mas apenas um deslocamento, uma limpeza social (Jardim \& Dimenstein, 2007).

O terceiro período surge com uma proposta de ruptura do paradigma psiquiátrico (Amarante, 2007). Temse, neste período, a Antipsiquiatria como possibilidade de desinstitucionalização na qual o papel da psiquiatria é posto em cheque e é reforçada a ideia de que a loucura é produzida na relação com a família e a sociedade.

A Antipsiquiatria - movimento constituído em torno de uma contestação geral das práticas psiquiátricas tradicionais (o termo foi cunhado por David Cooper, em $1967^{1}$ ) - propunha um questionamento desse modelo tradicional em múltiplas dimensões.

\footnotetext{
Uma nota importante a ser destacada refere-se ao conteúdo mitificado construído em torno da expressão "antipsiquiatria”. Laing (1989) declara que “(...) nunca disse que eu era antipsiquiatra: os antipsiquiatras são os outros, os médicos que mancham o nome da psiquiatria com a sua brutalidade, a sua crueldade" (p. 138). Por outro lado, Cooper (1979) coloca que: "Quando comecei a usar o termo anti-psiquiatria (...) não imaginava quanto inocentes que trabalham no campo da loucura - dos dois lados da suposta divisão entre loucos e os que tratam os loucos - seriam apanhados na rede mítica e repleta de misticismo que se gerou em torno dessa palavra aparentemente simples (...). Para mim, a anti-psiquiatria era e é inteiramente suscetível de definição (...)” (p. 69). A melhor definição para esta ideia vem do próprio Cooper (1979): "A anti-psiquiatria procurar inverter as normas do jogo psiquiátrico como um prelúdio para pôr fim a esses jogos” (p. 71).
}

Numa perspectiva "epistemológica”, ou seja, no que se refere à construção do saber em relação à patologia, a Antipsiquiatria apontava que a psiquiatria clássica estaria apoiada numa representação objetiva de "doença mental”, entendida como entidade mórbida, de fundo orgânico ou "mental", criando assim uma dicotomia organicismo versus mentalismo, sem contudo superá-los. Deste modo, a psiquiatria clássica estaria retida num modelo empiricista que não questionaria nem a essência nem as condições de possibilidade dos fenômenos psicopatológicos (Laing \& Cooper, 1964/1976; Laing, 1979).

Decorre disto uma concepção "antropológica" da noção de loucura que desconstitui o sujeito (Szasz, 1961/1982; Laing, 1989), o desqualifica enquanto experiência - pois a "doença” ou é do corpo (cerebral) ou da mente (um suposto psiquismo subjetivista) -; o que tem repercussões "políticas": esta noção faz com que o "louco" seja destituído de cidadania e, ao ser segregado em hospitais - aqui comparados a outras instituições totalitárias - leva-o a diversos modos de mortificação, como o alheamento, o despojamento material, a degradação da autoimagem, a violação da intimidade e a desqualificação de seu próprio ser no mundo, dentre outras (Goffman, 1961/1993; 1963/2003).

Por fim, promove um questionamento aos modos de "tratamento", centrados na hospitalização e no manicômio (por um lado), e na farmacoterapia como principal ferramenta (por outro), pondo em cheque, inclusive, os interesses da indústria farmacêutica na constituição de demandas de terapêutica (Szasz, 1961/1982; Cooper, 1967/1989). Tudo isto teria como consequência, o que comumente passou a ser chamado de "psiquiatrização do social”, ou seja, o fato de que, sob o prisma dessas apropriações, todos os aspectos da vida humana passariam a ser objetos "psiquiatrizáveis". Decorrente disto tudo, a Antipsiquiatria acaba por propor novas formas de entendimento de todas essas dimensões.

A tudo isto, contrapõe a ideia de um sofrimento psíquico não mais centrado no orgânico ou na interioridade de um sujeito, mas como um problema construído socialmente: a "doença mental” passa a ser um mito (Szasz, 1961/1982) e retoma-se os determinantes sociais da loucura (Laing \& Cooper, 1964/1982; Cooper, 1967/1989). Ainda nesta direção, faz-se um grande questionamento em relação às classificações psicopatológicas - nosológicas e nosográficas - como meras rotulações, propondo a loucura como uma linguagem (Cooper, 1979; Laing, 1979), e uma certa dialética, pautada na continuidade entre saúde/doença ou normal/patológico. No campo político, faz uma crítica social à psiquiatria, na direção de um resgate da cidadania do "louco", priorizando a dimensão política e social do tratamento da loucura. E, finalmente, à dimensão do tratamento, faz uma negação do modelo hospitalar, propondo serviços substitutivos; e um questionamento mordaz ao tratamento farmacológico - entendido como uma "camisa de força química" - propondo transforma- 
ções sociais como fundamento para a modificação da loucura (Szasz, 1961/1982; Laing \& Cooper, 1964/1982).

De todas essas críticas, resulta o clássico questionamento sobre a existência ou "realidade" da "doença mental" - mais claramente expresso na obra de Thomas Szasz (1961/1982), particularmente no O Mito da Doença Mental - e a construção de uma série de conceitos e ideias que falam do "sujeito" da psicopatologia, como a noção de “estigma”, desenvolvida por Erving Goffman (1963/2003). E tudo isto, junto, leva ao Movimento Antimanicomial.

No que nos interessa particularmente a este texto, é que - do ponto de vista filosófico - a Antipsiquiatria encontra boa parte de seus alicerces conceituais na Fenomenologia, em especial no que direciona para o rompimento com as lógicas determinísticas, apoiando-se particularmente nos pensamentos de Jaspers e Sartre (Schneider, 2009; Spohr \& Schneider, 2009) - mas tendo Sartre como interlocutor direto ou, como afirma Delacampagne (2004), "de Sartre à Antipsiquiatria, a via foi direta" (p. 27) - tendo, contudo, outros autores da fenomenologia como apoio, como Scheler, Merleau-Ponty e o próprio Husserl, que Laing (1981) ter lido após conhecer o Ser e o Nada, de Sartre ${ }^{2}$.

Já na Itália, a reflexão acerca do enfrentamento aos manicômios e a mudança na forma da atenção em Saúde Mental, surge com Franco Basaglia e seus colaboradores. Goulart (2007) aponta que a principal experiência, enquanto momento fundante do movimento antimanicomial e das mudanças subsequentes, foi a da cidade de Gorizia, no qual Basaglia atuou como diretor do hospital psiquiátrico, no início da década de 60.0 grande impacto dessa experiência foi a de que o encontro com o doente mental só seria possível se ele e todos os membros da comunidade, incluindo médicos, enfermeiros, entre outros, se encontrassem em um plano de liberdade e responsabilidade (Goulart, 2007). Enquanto a experiência de Gorizia foi o início de uma geração de profissionais de Saúde Mental que questionava os manicômios, a experiência seguinte, da cidade de Trieste, foi o local de consolidação de uma prática que influenciou diversos modelos de reforma, incluindo a brasileira. A experiência de Gorizia deu origem ao livro "A instituição negada" (Basaglia, 1968/1985), com relatos dos procedimentos e discussões que resultaram na gradativa abertura do hospital psiquiátrico.

Basaglia chegou a Gorizia, com uma concepção fenomenológico-existencial da relação médico-paciente, baseada na antropofenomenologia de Binswanger e de Minkowski, e na filosofia de Sartre (Goulart, 2007). Esta

\footnotetext{
Sobre a importância de Sartre na fundamentação do pensamento antipsiquiátrico de Laing e Cooper, basta assinalar que é o próprio filósofo francês que faz o prefácio ao livro Razão e Violência (Laing \& Cooper, 1964/1976), datado de 1963. Este livro, na realidade, é um ensaio sobre o pensamento sartreano, a partir de três ensaios, cada qual referente a uma de suas principais obras: Questions de Méthode e Saint Gênet (escritos por Cooper), e Critique de la Raison Dialectique (escrito por Laing).
}

influência pode ser percebida em suas ideias e em seus textos, como nos seus Escritos selecionados em saúde mental e reforma psiquiátrica, nos quais cita, além dos autores supramencionados, Foucault, Goffman, Husserl e Scheler, dentre outros (Basaglia, 2005). Tal concepção dizia de um outro olhar à doença mental e suas formas de cuidado. Basaglia discorre sobre a importância de se colocar entre parênteses a doença como categoria dada, para compreender o sujeito que se encontra à sua frente. Basaglia (2005) traz uma crítica à ciência, mais especificamente à ciência médica no campo da Psiquiatria, que caminha em busca de explicações para a "doença mental” numa posição metafísica dogmática, sob a égide da qual teve de confirmar suas hipóteses no corpo do próprio doente: encaixá-lo em suas hipóteses construídas.

Segundo Goulart (2007), Basaglia liderou uma passagem do movimento filosófico antropofenomenológico e existencialista para um movimento social e politizado. Sob a crítica do movimento filosófico e epistemológico da Fenomenologia, Basaglia questionou um fazer, uma situação social dentro de um contexto político. Pode-se compreender a crítica de Basaglia como uma metáfora da crítica de Husserl ou Dilthey ao modelo das ciências naturais, aplicada às ciências humanas. $\mathrm{O}$ que Basaglia traz, em sua crítica, é que ao tornar o doente mental um corpo objeto no qual se aloca uma doença, perde-se todo o contato com o sujeito em sofrimento, perde-se também o olhar atento ao fenômeno que se coloca. Ao invés desse olhar atento, há um olhar que é perpassado e direcionado por uma concepção teórica a respeito da doença mental.

Que a psiquiatria asilar reconheça, enfim, ter fracassado em seu encontro com o real, esquivando-se da verificação que - através daquela realidade - poderia ter efetuado. Uma vez que a realidade lhe escapou, ela limitou-se a continuar fazendo "literatura", elaborando suas teorias, enquanto o "doente" se via pagando as consequências dessa fratura - encerrado na única dimensão considerada adequada a ele: a segregação (Basaglia, 2005, p. 69).

O que Basaglia alerta é que, ao compreender e tratar os sujeitos com esta forma de sofrimento, criam-se outras questões que marcaram o sujeito como um sujeito que não sabe de si, sem liberdade nem responsabilidade sobre si. Esse isolamento é metaforicamente e fisicamente representado nos muros do manicômio.

A questão é que, mesmo a ciência tratando seu objeto de pesquisa como um objeto que pode ser compreendido por meio do afastamento subjetivo do pesquisador, o pesquisador, ainda sim, influencia seu objeto. Segundo Basaglia (2005), a consequência da ciência ter se ocupado da pesquisa ideológica da doença mental ao invés de se dedicar ao sujeito doente, ou em sofrimento, foi a "coisificação" do "doente mental”, sua exclusão, sua intimidação e "docilização”. As formas de tratamento manicomiais 
que foram uma consequência do olhar para o sujeito em sofrimento como um objeto que não possuía autoridade sob si mesmo nem voz para falar de si, tornaram este, um ser imóvel, sem objetivos, sem futuro nem interesses.

Uma das principais posturas preconizadas nessa nova compreensão fenomenológica, na qual se baseia Basaglia, é a de escutar o sujeito sem pressuposições e representações a respeito de suas possíveis patologias, na expectativa de superar os pré-julgamentos tradicionais e os estigmas derivados dessas representações. Nas palavras do autor:

Uma instituição que se pretende terapêutica deve tornar-se uma comunidade baseada na interação pré-reflexiva de todos os seus membros; uma instituição na qual a relação não seja a relação objetificante do senhor com o servo, ou de quem dá e quem recebe; na qual o doente não seja o último degrau de uma hierarquia baseada em valores estabelecidos de uma vez por todas pelo mais forte; na qual todos os membros possam - mediante a contestação recíproca e a dialetização das recíprocas posições - reconstruir o próprio corpo próprio e o próprio papel (Basaglia, 2005, p. 89).

Basaglia lutou por uma modificação no olhar que se tinha da loucura, para que pudesse ser vista como sofrimento existencial e social. O movimento social que surge com Basaglia e seus colaboradores, decorrente de suas experiências práticas de desinstitucionalização, seria denominado de Psiquiatria Democrática (Robortella, 2000).

A Reforma na assistência à Saúde Mental brasileira se baseia neste modelo italiano de desinstitucionalização. Então, como se verifica nas bases que norteiam a Reforma, ela é mais do que uma simples modificação física dos equipamentos de atenção em Saúde Mental; ela é o resultado de complexas discussões a respeito da compreensão sobre o conceito e os múltiplos sentidos com respeito à "loucura”.

\section{Atenção à saúde mental: contribuições da fenome- nologia}

Para a realização dessas discussões e reflexões a respeito da "doença mental" e da reforma dos modos de sua atenção, estaremos retomando o embasamento teórico da Fenomenologia, pois "[...] a maior parte das concepções atuais de saúde mental - em especial as críticas à formalização e aos tradicionalismos psiquiátricos - ali encontra apoio e estímulo" (Holanda, 2011, p. 120). A Fenomenologia influencia novos caminhos da compreensão da "loucura" na atualidade, tendo reverberação particular nos movimentos da Antipsiquiatria e da Luta Antimanicomial que ali encontram um alicerce teórico para suas propostas (Schneider, 2009; Holanda, 2011).
Fenomenologia é uma palavra de origem grega, phainómenon, que significa "aquilo que vem à luz", que "se mostra”, que se manifesta. Este termo foi utilizado por diversos pensadores como Kant e Hegel. Porém, a Fenomenologia, a que nos referimos, a que produziu uma revolução paradigmática, é a de Husserl (Holanda \& Freitas, 2011) e é a esta que aqui nos reportamos.

A Fenomenologia surge com Husserl no início do século XX como um questionamento sobre os rumos e fundamentos da ciência positiva. Toda a vida filosófica de Husserl é marcada por um sentimento de crise da cultura, e a própria Fenomenologia surge em meio à crise da ciência e da filosofia, sendo este um tema que acompanha o pensamento husserliano desde suas primeiras obras - como temos, por exemplo, em A Filosofia como Ciência de Rigor (Husserl, 1910/1965) - até seus últimos escritos - como em A Crise da Humanidade Europeia e a Filosofia, por exemplo (Husserl, 1935/2006). Essa crise diz respeito ao objetivismo da ciência, o mesmo ao qual Basaglia também se reporta, como mencionado anteriormente; crise de uma ciência fundamentada na positividade do conhecimento, mais especificamente na sua objetividade ao abrigo das construções subjetivas, que não deu conta da complexidade da vida, especialmente da vida humana (Husserl, 1935/2006; Dartigues, 2008). Paul Ricoeur (1986/2006), ao discutir a crise da humanidade europeia, discorre sobre a compreensão de Husserl de que esta crise está relacionada à significação das ciências para a vida.

Não se pretende com isto, realizar uma destruição da ciência positiva, visto que esta tem e deve ter seu espaço garantido. Carl Sagan (1995/2006) relembra a importância da ciência em seu livro $O$ mundo assombrado pelos demônios, ressaltando a importância da atitude científica de não acomodação em "verdades" ou hipóteses. O cientista deve compreender as limitações do ser humano em sua busca pelo conhecimento. Sagan (1995/2006) recorda que a ciência é construída por perguntas, e que o bom cientista é aquele que sempre se questionará sobre sua verdade. O próprio Husserl (1910/1965) faz uma defesa importante da necessidade de um saber "rigoroso", tendo a ciência como referência.

Porém, em meio a uma cultura positivista, as ciências do espírito ${ }^{3}$ se debatiam com as exigências da ciência naturalista que ditava todo o pensamento e aceitação da época. Assim, a psicologia busca se adequar criando uma psicologia explicativa que funciona por lógicas causais, segundo o princípio de causa e efeito. Ao considerar o homem, bem como toda a natureza, matematizável, ou seja explicado por sistemas formais, a ciência compreende o funcionamento psíquico tomando como referência o

\footnotetext{
Ciências do espírito, aqui é a expressão corrente entre os séculos XVIII e XIX, para se referir ao conjunto de ciências distintas das ciências naturais. Posteriormente, a partir do século XX, passa a denominar o conjunto de ciências do homem, que podemos atualmente circunscrever como o espectro das ciências humanas, antropológicas e sociais.
} 
modelo físico. Segundo Ricoeur (1986/2006), tanto a separação entre físico e psíquico como o naturalismo psicológico atestavam uma perda da subjetividade do homem.

Eu não sou o resultado ou o entrecruzamento de múltiplas causalidades que determinam meu corpo ou meu "psiquismo", eu não posso pensar-me como uma parte do mundo, como o simples objeto da biologia, da psicologia e da sociologia, nem fechar sobre mim o universo da ciência [...] eu sou a fonte absoluta; minha experiência não provém de meus antecedentes, de meu ambiente físico e social, ela caminha em direção a eles e os sustenta (Merleau-Ponty, 1945/1999, p. 3).

Começam a ser feitas críticas à adequação desse modelo de ciência à compreensão do ser humano. Wilhelm Dilthey é um exemplo dentre diferentes pensadores que questionam a universalidade do entendimento da ciência positiva. Em seu livro Idéias acerca de uma psicologia descritiva e analítica, de 1894, defende a impossibilidade das ciências do espírito funcionarem da mesma forma que as ciências naturais. Dilthey (1894/2008) coloca que as ciências do espírito, em oposição às ciências da natureza, não podem ser explicativas, somente compreensivas, já que seu objeto parte do homem, de dentro, como uma conexão viva.

A Fenomenologia surge na tentativa de dar conta desse desafio, buscando uma "terceira via" entre o raciocínio das ciências positivas, que considera apenas os aspectos objetivos do mundo e o discurso especulativo da metafísica, que acabava por produzir teorias "descoladas" do mundo e que se encerram em si mesmas (Dartigues, 2008). Para isso ela não se enfoca apenas no sujeito ou apenas no objeto, mas na relação entre eles. Ela se dá pela apreensão das relações do homem com o mundo. $\mathrm{O}$ mundo para a Fenomenologia é um objeto intencional, ou seja, que é referido por um sujeito e que faz referência a um sujeito. O homem também não é homem sem o mundo e, dado que a consciência é uma consciência intencional, é sempre uma consciência no mundo e voltada para o mundo, sempre direcionada ao mundo (Ricoeur, 1986/2006).

Husserl declara que fenômeno é tudo aquilo que se reporta a uma consciência. E o fenômeno subjetivo tem como característica central o fato de ser consciência-no-mundo e em relação, o que constitui como sendo necessariamente intersubjetivo, já que não pode ser considerado destacado do mundo, pois aí sim estaria fechado sobre si mesmo (Husserl, 1931/1980; Merleau-Ponty, 1945/1999; Drummond, 2007). O mundo não é apenas uma representação de uma consciência, mas é compartilhado. Por ser um fenômeno intersubjetivo, só o poderemos compreender, ou seja, co-apreender. Para que haja uma compreensão do fenômeno é necessário ir às coisas-mesmas, ou seja, ao fenômeno, à relação entre uma consciência e o mundo. A compreensão parte da descrição do fenômeno, de como ele se apresenta à percepção, e é preciso que esse contato seja sem prévias representações ou significações, para que se consiga uma descrição fiel (Holanda, 2009).

Husserl foi aluno de Brentano e traz em sua obra a influência deste. Uma das heranças diz respeito à construção de uma Psicologia Descritiva (Holanda \& Freitas, 2011). O entendimento de que a descrição deve preceder a explicação nas ciências do espírito também está presente na obra de Dilthey (1894/2008).

Para a realização de uma psicologia descritiva e analítica é necessário buscar expor a realidade integral da vida psíquica pela descrição, e quando possível, analisá-la. Para isso não é possível ir de encontro ao fenômeno com hipóteses, estas devem ser realizadas após o encontro com o próprio fenômeno (Dilthey, 1894/2008). Para compreender, conhecer, se aproximar de um fenômeno é necessária uma atitude de redução, ou seja de se colocar de lado pressuposições a respeito do fenômeno para vislumbrá-lo enquanto tal. É, como relata Basaglia, colocar o conceito de doença mental entre parênteses para se encontrar com o sujeito que se encontra a sua frente. A compreensão é um processo integrativo, não dissociativo, no qual toda perspectiva é válida pois nos auxilia a compreender diferentes aspectos do fenômeno.

Neste sentido, não mais falamos em "revelar" o mundo, oculto de algum modo, mas em des-velar sentidos, naquilo que o mundo se apresenta para uma consciência, não mais como "coisa", mas como fenômeno e, portanto, como dotado de um conjunto de significados que incluem - de modo inalienável todos os elementos da equação: sujeito, ato e mundo de fenômenos (Holanda, 2009, p. 88).

A Fenomenologia se estabelece como uma epistemologia enquanto crítica e teoria do conhecimento; mas é também uma filosofia, no sentido clássico do termo, enquanto reflexão sobre a realidade, e uma metodologia dessa mesma realidade. Além disso, é uma ciência, um conhecimento atento e aprofundado de alguma coisa (Holanda, 2009). A Fenomenologia é um marco na história da filosofia e influenciou diversas áreas do conhecimento (Holanda \& Freitas, 2011).

A revolução realizada pela Fenomenologia possibilitou uma nova forma de acesso ao mundo, especialmente o "mundo humano", recuperando as relações intersubjetivas e recolocando a subjetividade num contexto histórico e mundano. Recoloca-se o sujeito da ciência como ator; o homem é o centro, já que tudo que é percebido no mundo é referente a uma consciência e esta ligação entre mundo e consciência é colocada como enfoque (Holanda, 2011). É justamente na recolocação do homem como referência num contexto histórico e mundano que se dá fundamento para repensar a "doença mental". É contraditório para a Fenomenologia pensar em uma ciência centrada na patologia ao invés de estar centrada no ser. O enfoque não está na explicação das causas da doença, mas na com- 
preensão do significado que ela tem para o sujeito na experiência presente (Stockinger, 2007).

\section{Psiquiatria, psicopatologia fenomenológica e saúde mental}

Muito do que se entende hoje como "psicopatologia" se constrói alicerçado em fundamentos fenomenológicos (Schneider, 2009; Holanda, 2011). Ao longo da história podem ser encontrados alguns importantes psiquiatras fenomenólogos que contribuíram para a psicopatologia e para a compreensão da "doença mental”. Compreendese nesta pesquisa a psiquiatria como profissão prática e a psicopatologia como ciência propriamente dita, como caracterizou Karl Jaspers (1913/1987).

Apesar da Psicopatologia ser um campo anterior a Jaspers, é sua obra de 1913 - Psicopatologia Geral que funda e marca o início da chamada Psicopatologia Fenomenológica (Holanda, 2011). Esta obra realiza uma ampla discussão a respeito da Psicopatologia e descreve os fenômenos psicopatológicos. Jaspers é quem inaugura uma forma de se pensar as psicopatologias do ponto de vista fenomenológico, em uma posição epistemológica voltada à apreensão da transformação nas psicopatologias, em oposição à posição de enfoque na estabilidade (Messas, 2004).

Outros grandes nomes da psicopatologia fenomenológica que podem aqui ser referenciados são Ludwig Binswanger, Eugène Minkowski, Henri Ey, Viktor Emil von Gebsattel, Erwin Straus, Henricus Cornelius Rümke, Janse de Jonge, L.Van der Horst, Frederik J.J. Buytendijk e J.H.Van den Berg, dentre outros (Van den Berg, 1966/1994; Messas, 2004; Holanda, 2011). Deste rol, escolhemos Jaspers e Minkowski como autores para demonstrar a relação entre Psicopatologia, Psiquiatria e Fenomenologia. Não serão realizados aprofundamentos em seus trabalhos, mas será apresentada como a atitude fenomenológica os perpassa.

Jaspers, em sua Psicopatologia Geral (1913/1987) discorre a respeito de algumas posições que tomam frente ao desafio do psicopatologista. Seu objetivo não é criar uma compêndio de classificações didáticas e de fácil memorização, mas o de exercitar o pensamento psicopatológico dentro de um saber estruturado e de uma experiência metodológica que possa abranger a complexidade desse fenômeno. Logo na introdução, Jaspers realiza diversas discussões a respeito da tarefa de construção de uma psicopatologia geral, apontando que o objeto da psicopatologia é o homem como um todo. Mas alerta para os limites dessa ciência, pois não se pode reduzir o sujeito aos conceitos psicopatológicos: "Sempre o homem é algo mais do que se pode conhecer” (Jaspers, 1913/1987, p. 63). Por isso a atitude científica fundamental é estar aberto a todas as possibilidades de investigação empírica. Há de se esforçar para conhecer a vida psíquica por todos seus lados e por todas as vias.
A influência da Fenomenologia aparece em diversas partes de seu trabalho, como por exemplo, na compreensão da consciência enquanto relação intersubjetiva com o mundo; uma totalidade de um mundo interior e um mundo ambiente. Jaspers não considera a consciência como objeto, mas enquanto fluxo, herança da compreensão de William James. Ele também ressalta que trabalha com o que é vivenciado, com a vida psíquica imediatamente dada. Jaspers alerta acerca dos preconceitos, ou seja, conceitos anteriores que anuviam nosso olhar ao fenômeno. Um dos exemplos trazidos pelo autor é o preconceito teórico, pois corre o sério risco de se voltar somente ao que confirma a teoria em questão. Também critica a naturalização da vida psíquica, colocando como tarefa constante a abstração das teorias e outros preconceitos em busca de um acolhimento dos dados.

Com respeito ao diagnóstico, coloca que este é o menos essencial no trabalho do psicopatologista, e que, apesar de fazer parte do processo, é a última compreensão em um caso. Realiza também uma discussão a respeito dos métodos, abrangendo várias possibilidades metodológicas, sempre se perguntando como cada um pode ampliar, aprofundar, alargar a experiência, levando em conta sua relevância e seus limites. Ele também aponta a importância das outras ciências, com diferentes métodos e conceitos. Em suas palavras: "A consciência metodológica nos mantém frente à realidade que deve ser apreendida sempre de novo. A dogmática do ser nos tranca num saber que, como um véu, se antepõe a toda nova experiência” (Jaspers, 1913/1987, p. 58).

A história da Psicopatologia Fenomenológica remonta também à figura de Dilthey (Holanda, 2011). Segundo Van den Berg (1966/1994), pode-se verificar em Jaspers a influência de Dilthey em seu trabalho e o fato de ter sido o primeiro a introduzir na psiquiatria suas ideias. Para Jaspers o método explicativo também será utilizado para a compreensão da psicopatologia, porém, esse não abarca a complexidade deste fenômeno, defendendo o método compreensivo como aquele capaz de acolher a subjetividade.

Tal qual outros psicopatologistas fenomenólogos (Minkowski, Van den Berg, entre outros), Jaspers irá discorrer a respeito da importância dos casos raros para compreender os casos triviais. Ele defende que muitas vezes o aprofundamento em um caso particular ensina o que é geral para outros casos. Não há necessidade de exemplos de série, visto que a compreensão da psicopatologia não está na quantidade, mas na qualidade dos casos estudados. Um exemplo disto é o livro O Paciente Psiquiátrico de Van den Berg (1966/1994), no qual se descreve a condição de um paciente. Ele escolhe um só sujeito, pois acredita que um paciente pode englobar toda a psicopatologia.

Minkowski é um psiquiatra francês de grande influência na história da Fenomenologia e na psiquiatria da França. No início do século XX introduziu a obra de Husserl em seu país; foi membro fundador e primeiro presidente do grupo Évolution Psychiatrique, em 1925. 
Minkowski trabalhou com Bleuler em Zurique (entre 1912 e 1914), e conviveu durante este período com Binswanger, Jung e Rorschach (Abreu e Silva Neto, 2004). Apesar de sua importância, especialmente na Psicopatologia Fenomenológica, a obra deste autor não é muito conhecida no Brasil. Nenhum de seus livros foi traduzido para o português (Abreu \& Silva Neto, 2004).

A psicopatologia para Minkowski (1968/2000) constitui uma psicologia do patológico e não uma patologia do psicológico. Ou seja, a "loucura" é compreendida enquanto modo de estar no mundo, não errado ou doentio, mas apenas como mais uma forma de estar em relação com o mundo. Desconstrói-se, deste modo, a noção de "normalidade", enquanto padrão absoluto que define os "desvios mórbidos" da vida mental.

Ao conhecer a experiência humana como intrinsecamente pática, fundada sobre o pathos da paixão e do sofrimento, a psicologia do patológico tem por tarefa a descrição de formas singulares de existência e de estar-no-mundo. A psicologia do patológico se refere à descrição global da experiência vivida pelo enfermo e, global, nesse caso, implica em visão integrada do todo psíquico com o todo vivido pela pessoa. Com tal atitude metodológica, Minkowski aborda o fenômeno de pathos visando exprimir seu fundo existencial, antes de realizar um recenseamento de sintomas e de alterações na alma.

Minkowski procurou desenvolver uma ciência antropológica, já que buscou o homem enquanto referência. Entende-se por "antropologia” a ciência da totalidade do fenômeno humano. Uma visão antropológica da psicopatologia busca compreender as modalidades existenciais do homem, levando em conta sua singularidade com o objetivo de elucidar os sentidos dos sintomas. Nesta "visão antropológica” da psicopatologia se propõe tentar alcançar um quadro mais amplo da estrutura existencial do homem (Holanda, 2001).

Em seu livro A Esquizofrenia, publicado originalmente em 1927, Minkowski alega que o método utilizado não se deteve à psicopatologia, mas sim a aspectos da vida. $\mathrm{O}$ fenômeno psicopatológico não é delimitado por seu caráter mórbido ou doentio, nem por comparação com a normalidade, e sim por se constituir como uma outra forma de ser (Pereira, 2000). Minkowski (1968/2000) concorda com as ideias de Bergson sobre a impossibilidade de quantificar e mensurar aspectos mais fundamentais da existência, tais como a vivência de pathos; recorre ainda a suas próprias experiências clínicas para se aproximar de tal fenômeno.

Segundo Minkowski (1968/2000), o enfoque clínico ou teórico ao colocar seu olhar sobre o pathos deve separar seus processos em si das alterações nos desempenhos mentais; deve-se também abrir mão da exatidão, exigida pela ciência exata. Na Psicologia do Pathos, os sintomas servem a um fim (Pessotti, 2006), sendo como a carne, sangue e nervos, apenas finas camadas que envolvem um segredo invisível, uma história que mora em nós; os sintomas são apenas a superfície que protege o fenômeno pático. "O paciente não é um caso, e sim uma pessoa, cuja linguagem da alma se expressa no corpo, no tempo do relógio e no tempo vivido" (Costa \& Medeiros, 2009, p. 383).

Minkowski discorre sobre o sofrimento como um momento da existência: "O sofrimento não é absolutamente sinal de desequilíbrio, não há nada de anormal nele. Ele faz 'normalmente' parte de nossa existência [...] o sofrimento humano é o que nos revela o aspecto mais aparente, mas dramático e mais “vivo”' (Minkowski, 1968/2000, p. 164). Na psicopatologia fenomenológica o enfoque está, pois, no "mundo-vida" do indivíduo, no significado de "ser patológico"; na compreensão das modalidades existenciais do homem, seus "modos de ser" e as "maneiras de vivenciar" as psicopatologias (Holanda, 2001). Buscase não apenas uma pura descrição dos fenômenos psicopatológicos, mas a sua essência, transcendendo suas manifestações particulares (Messas, 2004).

À fenomenologia compete apresentar de maneira viva, analisar em suas relações de parentesco, delimitar, distinguir da forma mais precisa possível e designar com termos fixos os estados psíquicos que os pacientes realmente vivenciam. (Jaspers, 1913/1987, p. 71)

A característica fundamental da psicopatologia fenomenológica é a busca pela compreensão das vivências psíquicas tais e quais realmente experimentadas pelos pacientes. "Uma das principais características da fenomenologia é que não visa à procura de uma teoria sutil, mas apenas a um plausível conhecimento íntimo" (Van den Berg, 1966/1994, p. 8). A Fenomenologia busca olhar o homem e seu sofrimento não como um entrecruzamento de múltiplas causalidades que o determinam, mas como uma singularidade que se apresenta à compreensão. A Fenomenologia da psicopatologia não irá se focar na doença, mas na expressividade, contexto e forma de ser do sujeito que se apresenta.

Já não deveríamos retroceder ante à tarefa, por extensa que esta seja, que consistiria em estudar todas as manifestações, o mesmo que todas as atividades e todos os movimento da alma, em sua variedade e em suas matrizes, que chega a fixar e a expressar a linguagem. Em todos os casos, nada nos impede de nos comprometermos a esta via. Quiçá seja essa também um meio de liberar a psicologia do cerco estreito no qual, em virtude dos princípios que ela considera científicos, se encerra, para aproximá-la novamente do humano e do vivido, para retorná-la a grande arena da vida. E a psicopatologia se beneficiaria igualmente isto. Perspectivas... (Minkowski, 1927/1960, p. 218).

Minkowski finaliza seu livro "A Esquizofrenia” com esta passagem, alertando à tarefa que é também proposta pela Fenomenologia, a de se aproximar da experiência 
vivida. Uma tarefa que como coloca Jaspers (1913/1987), exige esforço, mas se torna a forma mais coerente para se aproximar da complexidade do fenômeno humano.

\section{Considerações finais}

A Reforma da Saúde Mental brasileira é influenciada pelo modelo de desinstitucionalização italiano, cuja principal influência são o pensamento e as experiências de Franco Basaglia. Como pode-se observar, Basaglia possui influência da compreensão fenomenológica e de psiquiatras fenomenólogos. Igualmente a experiência de Laing e Cooper, com a Antipsiquiatria inglesa, trouxe alternativas e reflexões de forte cunho fenomenológico e existencial para o movimento da Reforma na atenção à saúde mental brasileira.

A perspectiva de reabilitação psicossocial; de reintegração do sujeito da saúde mental em seu contexto familiar, social, econômico e cultural; a ideia de "território", devem muito ao resgate da subjetividade contextualizada propugnada por uma série de pensadores da filosofia e psiquiatria fenomenológicas. Como podemos observar igualmente na ideia de "rede", proposta pela referência aos Centros de Atenção Psicossocial (CAPS):

Para constituir essa rede, todos os recursos afetivos (relações pessoais, familiares, amigos etc.), sanitários (serviços de saúde), sociais (moradia, trabalho, escola, esporte etc.), econômicos (dinheiro, previdência etc.), culturais, religiosos e de lazer estão convocados para potencializar as equipes de saúde nos esforços de cuidado e reabilitação psicossocial (Ministério da Saúde, 2004, p. 11).

A influência da fenomenologia no pensamento de Basaglia e de psiquiatras como Jaspers e Minkowski está na possibilidade de colocar a doença entre parênteses para que se possa alcançar o fenômeno em si, neste caso, o sujeito. Uma aparente pequena mudança que traz grandes consequências. Uma delas é o posicionamento do sujeito como centro da questão tanto do estudo psicopatológico quanto da atenção à saúde mental. Como traz Basaglia, as formas de tratamento são consequências do olhar que se tem à doença mental.

Dilthey e Husserl discorrem a respeito da impossibilidade das formas de explicação das ciências naturais darem conta da complexidade das ciências do espírito; trazendo como alternativa o método compreensivo que pretende ir ao encontro do fenômeno e do co-apreender. Jaspers constrói sua Psicopatologia Geral demonstrando sua forma de pensar a psicopatologia, cujo objeto é o homem como um todo. Jaspers busca compreender o homem sob diferentes ângulos e ao mesmo tempo com especial cuidado às diferentes possibilidades de pré-conceitos. Minkowski busca a compreensão das psicopatologias como modos de estar no mundo, o que desconstrói a noção de anormalidade ligada à psicopatologia. Colocando o homem como centro de referência ao invés de sua doença. Tanto Minkowski, quanto Jaspers e Basaglia buscam compreender aspectos mais amplos dos fenômenos psicopatológicos: sua expressividade, contexto e formas de ser; um sofrimento existencial e social.

As discussões propostas pela leitura fenomenológica apontam mesmo para um novo questionamento sobre o que é saúde e doença - como encontramos nos clássicos pensadores da psiquiatria fenomenológica -, que encontra eco nos contemporâneos questionamentos sobre a noção de "saúde mental", por exemplo (Amarante, 2007). Mas é, fundamentalmente, uma "mudança de paradigma":

O processo de desinstitucionalização torna-se agora reconstrução da complexidade do objeto. A ênfase não é mais colocada no processo de "cura" mas no projeto de "invenção da saúde" e de "reprodução social do paciente”. (...) O problema não é a cura (a vida produtiva) mas a produção de vida, de sentido, de sociabilidade, a utilização das formas (dos espaços coletivos) de convivência dispersa (Rotelli, De Leonardis \& Mauri, 1986/2001, p. 30. Grifos no original).

A "simplicidade destas mudanças ajuda a compreender como a desinstitucionalização é sobretudo um trabalho terapêutico, voltado para a reconstituição das pessoas, enquanto pessoas que sofrem, como sujeitos" (Rotelli, De Leonardis \& Mauri, 1986/2001, p. 33). E este é um do principais focos do pensamento fenomenológico: o resgate da subjetividade.

A fenomenologia influencia diferentes áreas do conhecimento, dentre elas a saúde mental e a psicopatologia. O processo de reforma na Saúde Mental brasileira e as concepções atuais de saúde mental sofreram influências e também encontraram fundamento e inspiração nela. Espera-se que essa herança continue a ser fonte de inspiração e recurso de fundamentação para que o processo de reforma da atenção à saúde mental não se perca em aspectos meramente estruturais ou políticos. Já que como bem aponta os fenomenólogos citados ao longo do artigo, o ponto central de preocupação deve ser o sujeito.

\section{Referências}

Abreu e Silva Neto, N. (2004). A Atualidade da Obra de Eugène Minkowski (1885-1972). Boletim Academia Paulista de Psicologia, XXIV(2), 50-62.

Amarante, P. (2007). Saúde mental e Atenção psicossocial. Rio de Janeiro: Fiocruz.

Basaglia, F. (1979). Psiquiatria alternativa: contra o pessimismo da razão, o otimismo da prática. (Vol. 1). Tradução de Sonia Soianesi e Maria Celeste Marcondes. São Paulo: Editora Brasil Debates. 
Basaglia, F. (1985). A Instituição Negada: Relato de um Hospital Psiquiátrico. São Paulo: Graal (Original de 1968).

Basaglia, F. (2005). Escritos selecionados em saúde mental e reforma psiquiátrica. Organização: Paulo Amarante. Tradução de Joana Angélica d’Ávila Melo. Rio de Janeiro: Garamond.

Brasil (2001). Lei 10.216 de 6 de abril de 2001 (Dispõe sobre a proteção e os direitos das pessoas portadoras de transtornos mentais e redireciona o modelo assistencial em saúde mental). Brasília: Senado Federal. Disponível em http:// www.ccs.saude.gov.br/saude_mental/legis/legis1.asp

Cooper, D. (1979). A Gramática da Vida. Lisboa: Editorial Presença.

Cooper, D. (1989). Psiquiatria e Antipsiquiatria. São Paulo: Perspectiva (Original publicado em 1967).

Costa, V. E. S. M., \& Medeiros, M. (2009). O tempo vivido na perspectiva fenomenológica de Eugène Minkowski. Psicologia em Estudo, 14 (2), 375-383.

Dartigues, A. (2008). O que é fenomenologia? Tradução Maria José J. G. de Almeida. (10 ed.). São Paulo: Centauro.

Delacampagne, C. (2004). A contestação antipsiquiátrica. Mental (Online), 2 (2), 27-34.

Dilthey, W. (2008). Idéias acerca de uma Psicologia Descritiva e Analítica. Tradução de Artur Morão. Covilhã: LusoSofia (Original publicado em 1894).

Drummond, J.J. (2007). Historical Dictionary of Husserl's Philosophy. New York: Hardcover.

Goffman, E. (1996). Manicômios, Prisões e Conventos. São Paulo: Perspectiva (Original publicado em 1961).

Goffman, E. (2003). Estigma. Notas sobre uma manipulação da identidade deteriorada. Rio de Janeiro: LTC (Original de 1963).

Goulart, M. S. (2007). As raízes italianas do movimento antimanicomial. São Paulo: Casa do Psicólogo.

Holanda, A. (2001). Psicopatologia, exotismo e diversidade: ensaio de antropologia da psicopatologia. Psicologia em Estudo, 6(2), 29-38.

Holanda, A. (2009). Fenomenologia e Psicologia: diálogos e interlocuções. Revista da Abordagem Gestáltica, 15(2), 87-92.

Holanda, A. F. (2011). Gênese e histórico da psicopatologia fenomenológica. Em V. A. Angerami (Org.). Psicoterapia e Brasilidade. São Paulo: Cortez.

Holanda, A. F. \& Freitas, J. (2011). Fenomenologia e Psicologia: Vinculações. Em Adão José Peixoto, Fenomenologia diálogos possíveis (pp. 97-112). Campinas: Alínea Editora.

Husserl, E. (1965). Filosofia como Ciência Rigorosa. Lisboa: Atlantida (Original de 1910).

Husserl, E. (1980). Méditations Cartésiennes. Introduction à la phénoménologie, Paris: Librairie Philosophique J.Vrin (Original de 1931).
Husserl, E. (2006). Crise da Humanidade Europeia e a Filosofia. Lisboa: LusoSofia (Original de 1935).

Jaspers, K. (1987). Psicopatologia Geral. Tradução Samuel Penna Reis. Rio de Janeiro: Atheneu (Original publicado em 1913).

Jardim, K. \& Dimenstein, M. (2007). Risco e crise: pensando os pilares da urgência psiquiátrica. Psicologia em Revista, 13(1), 169-190.

Laing, R. (1981). Sobre loucos e sãos. Entrevista a Vincenzo Caretti. São Paulo: Brasiliense.

Laing, R. (1989). A loucura. Entrevistas do Le Monde (pp. 137-141). São Paulo: Editora Ática.

Laing, R. \& Cooper, D. (1976). Razão e Violência. Petrópolis: Vozes (Original publicado em 1964).

Merleau-Ponty, M. (1999). Fenomenologia da percepção. São Paulo: Martins Fontes (Original publicado em 1945).

Messas, G. P. (2004). Psicopatologia e Transformação: Um esboço Fenômeno-Estrutural. São Paulo: Casa do Psicólogo.

Ministério da Saúde (2004). Saúde Mental no SUS. Os Centros de Atenção Psicossocial. Brasília: Ministério da Saúde.

Ministério da Saúde (2005). Reforma psiquiátrica e política de saúde mental no Brasil. Brasília: Ministério da Saúde/ OPAS.

Minkowski, E. (1960). La esquizofrenia: Psicopatología de los esquizoides y los esquizofrénicos. Buenos Aires: Paidos (Original publicado em 1927).

Minkowski, E. (2000). Breves reflexões a respeito do sofrimento (aspecto pático da existência). Revista Latinoamericana de Psicopatologia Fundamental, 3(4), 156-164 (Original publicado em 1968).

Pereira, M. E. (2000). Minkowski ou a psicopatologia como psicologia do pathos humano. Revista Latinoamericana de Psicopatologia Fundamental, III, 153-155.

Pessotti, I. (2006). Sobre a teoria da loucura no século XX. Temas em Psicologia, XIV(2), Dezembro, 113-123.

Ricoeur, P. (2006). Na escola da fenomenologia. Rio de Janeiro: Vozes (Original publicado em 1986).

Robortella, S. C. (2000). Relatos de usuários de saúde mental em liberdade: o direito de existir. Dissertação de Mestrado em Saúde Coletiva, Universidade Estadual de Campinas, Campinas, São Paulo.

Rotelli, F.; De Leonardis, O. \& Mauri, D. (2001). Desinstitucionalização, uma outra via. In Franco Rotelli, Ota De Leonardis \& Diana Mauri, Desinstitucionalização (pp. 17-60). São Paulo: Editora Hucitec (Original publicado em 1986).

Sagan, C. (2006). O mundo assombrado pelos demônios. Tradução Ephraim Ferreira Alves. São Paulo: Companhia de Bolso (Original publicado em 1995). 
Schneider, D. R. (2009). Caminhos históricos e epistemológicos da psicopatologia: contribuições da fenomenologia e existencialismo. Cadernos Brasileiros de Saúde Mental, 1 (2), 62-76.

Spohr, B. \& Schneider, D. R. (2009). Bases Epistemológicas da Antipsiquiatria: A Influência do Existencialismo de Sartre. Revista da Abordagem Gestáltica, 15 (2), 115-125.

Stockinger, R. C. (2007). Reforma Psiquiátrica Brasileira: Perspectivas Humanistas e Existenciais. Rio de Janeiro: Vozes.

Szasz, T. (1982). O Mito da Doença Mental. São Paulo: Círculo do Livro (Original publicado em 1961).

Van den Berg, J. H. (1994). O Paciente Psiquiátrico. Campinas: Editorial Psy (Original publicado em 1966).

Mariana Cardoso Puchivailo - Musicoterapeuta pela Faculdade de Artes do Paraná (FAP), Psicóloga e Mestranda em Psicologia pela Universidade Federal do Paraná (UFPR) e Pós-graduada em Psicologia Analítica pela Pontifícia Universidade Católica do Paraná (PUCP-PR). Endereço Institucional: Mestrado em Psicologia. Praça Santos Andrade, 50 ( $2^{\circ}$ Andar $)$, Sala 216. Curitiba, PR. E-mail: marianapuchivailo@yahoo.com.br

Guilherme Bertassoni da Silva - Psicólogo graduado pela Universidade Federal do Paraná (UFPR), Especialista em Saúde da Família/Saúde Coletiva e em Saúde Mental, Psicopatologia e Psicanálise pela Pontifícia Universidade Católica do Paraná (PUC-PR), Mestrando em Psicologia pela Universidade Federal do Paraná (UFPR) e Vice-Presidente do Conselho Regional de Psicologia (8 ${ }^{\text {a }}$ Região).E-mail: silvapsi@hotmail.com

Adriano Furtado Holanda - Psicólogo, Mestre em Psicologia pela Universidade de Brasília (UnB) e Doutor em Psicologia pela Pontifícia Universidade Católica de Campinas (PUC-Campinas); Professor Adjunto do Departamento de Psicologia e do Programa de Mestrado em Psicologia da Universidade Federal do Paraná (UFPR); Coordenador do Laboratório de Fenomenologia e Subjetividade (LabFeno/UFPR) e Primeiro-Presidente da Associação Brasileira de Psicologia Fenomenológica (ABRAPFE).E-mail: aholanda@yahoo.com

Recebido em 12.06 .13 Aceito em 15.12.13 